\title{
The Method and Basis of Dam Location Selection
}

\author{
Take an Example of Kariba Dam \\ Yuxuan Yang ${ }^{1, a}$
}

${ }^{1}$ School of North China Electric Power University, Baoding 071000, China;

\section{a1377758844@qq.com}

\begin{abstract}
The choosing of dam location is a very important part of water conservancy project. Through the scientific dam location selection, the quality of water conservancy project can be improved [1]; In order to introduce the process of dam location selection. Take an example of the Kariba dam, picking 24 possible building positions. Then use Technique for Order Preference by Similarity to an Ideal Solution (TOPSIS) to establish the comprehensive evaluating model of the 6 indicators of the positions such as river width, annual average precipitation, etc. The possible positions can be divided into 3 kinds according to their main function. The kinds are water resource controlling dam, water storage power generation damp and the water storage irrigation dam. After establishing the linear programing model, final decision is that the total amount of the new dam is 15.
\end{abstract}

Keywords: Dam location, TOPSIS, Liner Programing

\section{Introduction}

Since its completion in the late 1950s, the Kaliba Dam has provided more than 50 per cent of electricity for Zambia and Zimbabwe, benefiting some 4.5 million people, but the loss of potential safety risks has been delayed. Zambia River Authority said that if not timely to take remedial measures, the dam may collapse. The current dam repair project has been started, financing a total of 300 million US dollars, by the African Development Bank, the European Union and the two governments co-financing. In addition, the World Bank and the Swedish government provided \$ 75 million in IDA loans and \$ 25 million respectively.[2]

Rebuilding is one of methods to maintenance a dam that needs repairing. Rebuilding means removing the existing dam and building new dams to work. Take an example of Kariba Dam, we know that the existing Kariba dam took 4 years to build. Considering the development of constructing technology, We assume that it will take 4 years to remove and build. The removing project will begin at 2017.We estimate that the new Kariba dam will be put into use formally in 2021. We still pick our investigating period as 2017 2033. The stable operation time is 12 years. We will give an assessment of the repairing solution in this period based on the assumptions.

When we build a new dam, we need to consider many indicators. The main indicators are the distribution of water resource, farm lands and population. Then we pick the annual rainfall, river width, farmland area, population, topsoil sand fraction, the amount of natural disasters such as earthquake, debris flow, fire in the past 50 years.

\section{Dam location choosing}

\section{1 . Picking the possible building positions for the new dam}

We use Google Earth to pick 24 possible positions that can satisfy the need of power generation, irrigation, water resource control, etc. The main foundation is the distribution of water resource, farm lands and population. Then we pick the annual rainfall, river width, farmland area, population, topsoil sand fraction, the amount of natural disasters such as earthquake, debris flow, fire in the past 50 years. Based on the above indicators, we use the TOPSIS method to evaluate the 24 positions. The specific 
data is in table 3.We use HWSD (Harmonized World Soil Database) to get the soil data. The distribution of the new dam in the Zambezi area is shown in Fig 1.

In the 6 indicators we picked above. The annual average precipitation and the river width are the influencing factors o'f the need of water resource controlling dam. The population is the influencing factor of Water storage power generation dam,. The farmland area is for the water resource irrigation dams.

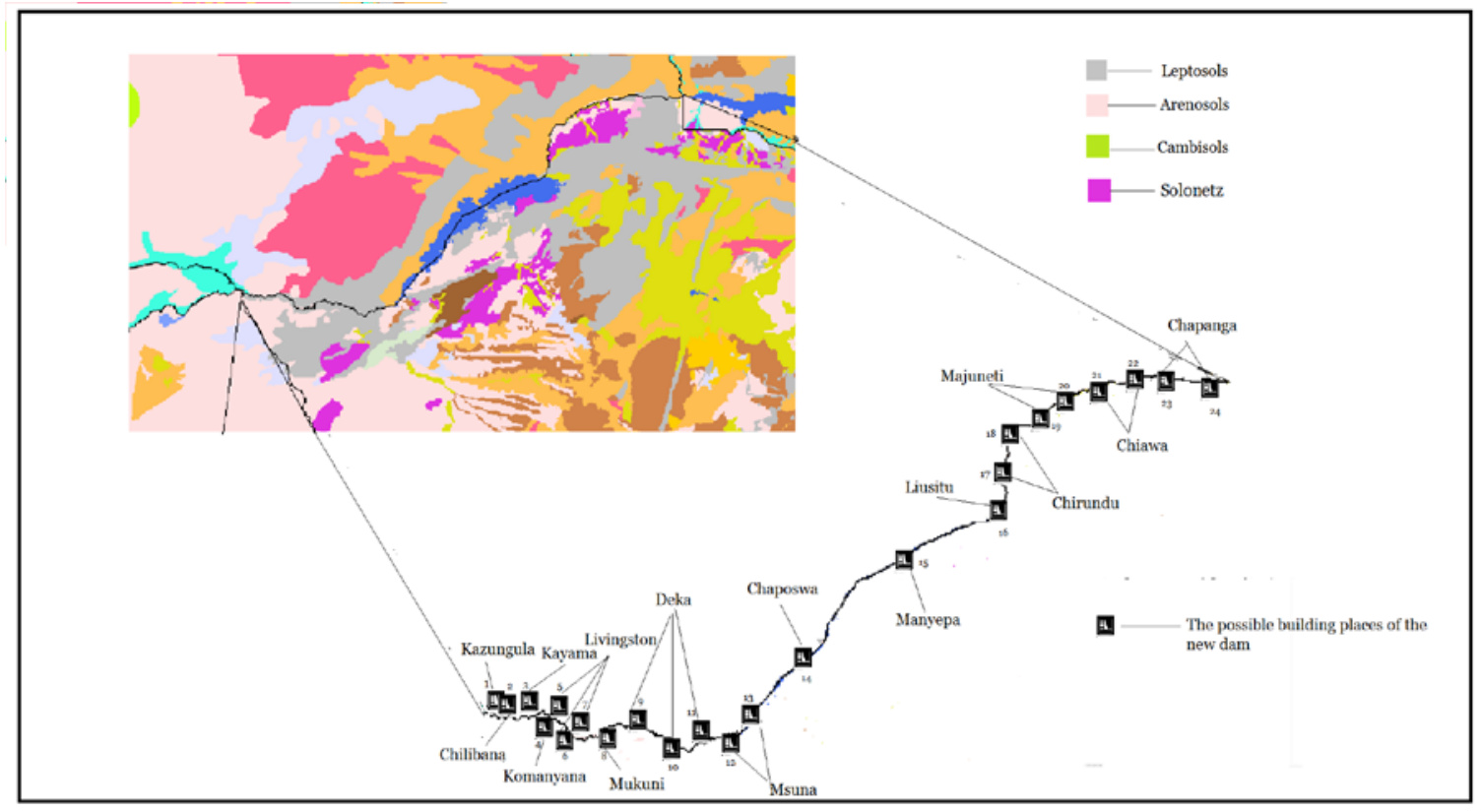

Fig 1. The distribution of the new dam and the soil properties

\subsection{Evaluation of possible positions}

We use to express $j t h(j=1,2, \ldots, 6)$ indicator data of the ith position(i=1,2, .,24).Then we can get the indicator matrix . After the standardization of $\mathrm{A}$, we get the normalized indicator matrix .

In matrix B:

$$
b_{i j}=a_{i j} / \sqrt{\sum_{i=1}^{24} a_{i j}{ }^{2}}, i=1,2, \ldots, 24 ; j=1,2, \ldots, 6
$$

The weigh vector of the above indicators, The weighted normative matrix is .

In matrix C:

$$
c_{i j}=w_{j} \bullet b_{i j}, i=1,2, \ldots, 24 ; j=1,2, \ldots, 6
$$

We define the positive ideal solution and negative ideal solution. We assume the jth attribute value of is .The jth attribute value of is .

The positive ideal solution is:

$$
c_{j}^{*}=\left\{\begin{array}{l}
\max _{i} c_{i j}, \\
\min _{i} c_{i j},
\end{array} j=1,2, \ldots, 6\right.
$$

The negative ideal solution is

$$
c_{j}^{0}=\left\{\begin{array}{l}
\min _{i} c_{i j}, \\
\max _{i} c_{i j},
\end{array} j=1,2, \ldots, 6\right.
$$

We calculate the distances between the indicator data and the ideal solutions: 


$$
\begin{gathered}
S_{i}^{*}=\sqrt{\sum_{j=1}^{24}\left(c_{i j}-c_{j}^{*}\right)^{2}}, i=1,2, \ldots, 24 \\
S_{i}{ }^{0}=\sqrt{\sum_{j=1}^{24}\left(c_{i j}-c_{j}{ }^{0}\right)^{2}}, i=1,2, \ldots, 24
\end{gathered}
$$

Then we can get the comprehensive evaluate index :

$$
f_{i}^{*}=s_{i}^{0} /\left(s_{i}^{0}+s_{i}^{*}\right), i=1,2, \ldots, 24
$$

We give an order to the 24 positions according to their Then we take the top 20 locations as pre-built dam site for the further planning.

\subsection{The decision of the dam's amount}

We can divide the new dams into three kinds according to their main function. The three kinds are: water resource controlling, Water storage power generation, water resource irrigation. We assume that the amount of each kind of new dams is $x, y, z$, In order to make this new system of dams have the same overall water management capabilities as the existing Kariba Dam while providing the same or greater levels of protection and water management options for Lake Kariba that are in place with the existing dam. The new dam system should satisfy the following demands:

(1) The total amount of the new dams should be in the range of 10 20

(2) The total storage of the new system should be same with the existing dam.

(3) The amount of electricity generated indirectly by the new dam system is not less than the amount of electricity generated by existing dams.

(4) The amount of available water for irrigation in the new dam system should not be less than the amount of irrigation water available from existing dams;

We assume the capacity specification of the three kinds of new dams is 18.5 billion cubic meters 9.25 billion cubic meters and 9.25 billion cubic meters. In order to satisfy the above demands, we establish the linear programming model for the amounts of the three kinds of dam.

The model is:

$$
\begin{gathered}
\min : n=x+y+z \\
\text { s.t. }\left\{\begin{array}{l}
10 \leq x+y+z \leq 20 \\
132 x+66 y+66 z \geq 1320 \\
92.5 x+185 y+92.5 z=1850 \\
6.078 x+6.078 y+12.156 z \geq 121.56
\end{array}\right.
\end{gathered}
$$

We use Matlab to get the solution of the above model:

$$
\left\{\begin{array}{l}
x=5 \\
y=5, \\
z=5 \\
n=15
\end{array}\right.
$$

Therefore, there will be 15 dams in the new dam system. Each kind will have 5 dams to satisfy the demands.

\subsection{Final decision of the new dams' location}

In the 6 indicators we picked in 3.1.The annual average precipitation and the river width are the influencing factors of the need of water resource controlling dam. The population is the influencing factor of Water storage power generation dam,. The farmland area is for the water resource irrigation dams. According to the different needs, we do weight and vector processing to the possible positions to get the needing coefficient of them. Then we give more targeted order of the positions. 
According to the evaluation coefficient, the numbers of the fifteen satisfying positions are 3,4,5,7,14,15,16,17,18,19,20,21,22,23,24. The areas' names are Kayama, Komanyana, Simonga, Mukuni, Chatugwa, Lusitu, Chirundu, Majuaneti, Chiawa, Chapanga, Katemo, Mpazangwo, Luangwa. Specifically, we will build 5 water resource controlling dams in Chirundu, Simonga, Majuaneti, Mukuni, Komanyana. We will also build 5 water storage power generation dams in Chiawa, Chapanga, Lusitu, Katemo, Mpazangwo. There will also be an irrigation dam in Kayama, two in Chatugwa and another two in Luangwa. The distribution is shown in Fig.2.

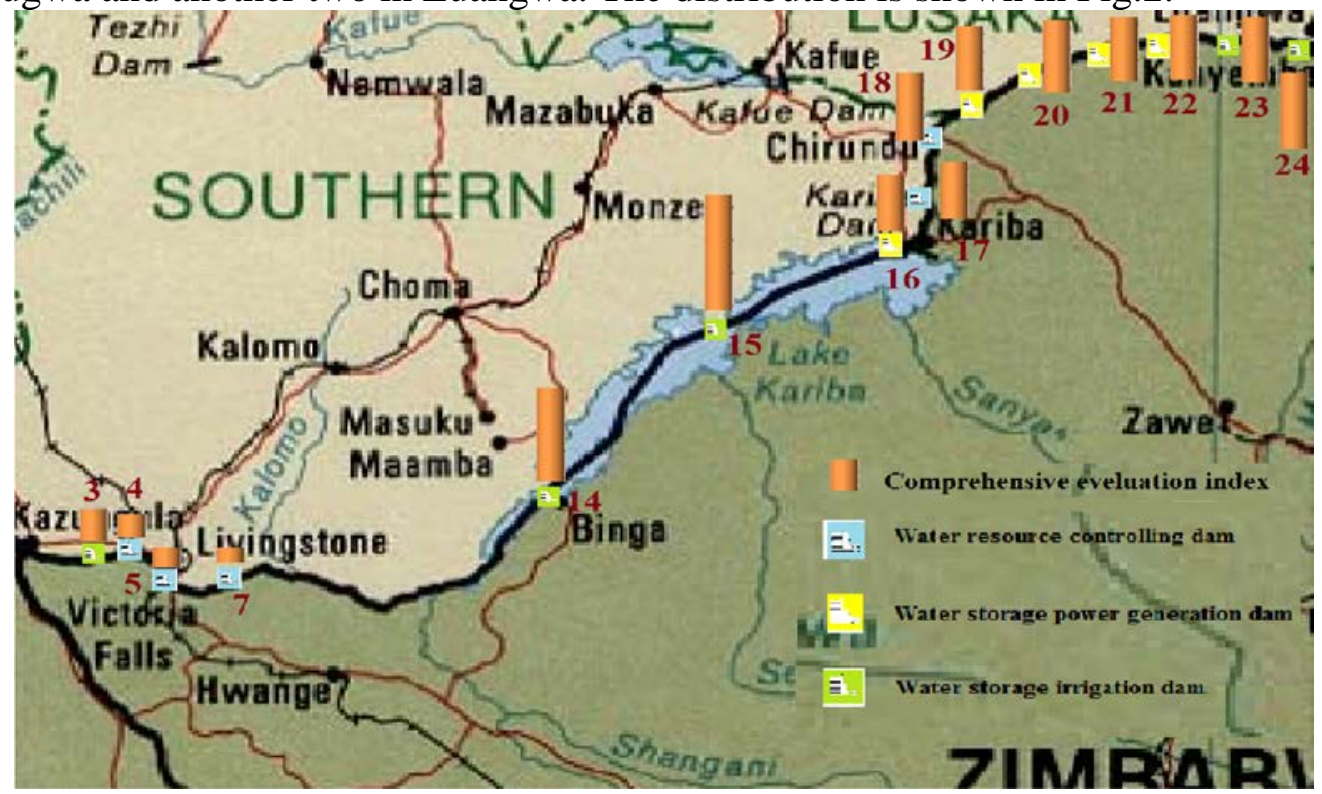

Fig 2. The final decision of the new dam system

\section{The cost and profit of the new dams}

The construction of a new multi-dam system would require the removal of existing dams and the rebuilding of dams at the 15 selected dam sites. We assume that the cost of building a dam is directly proportional to the dam's capacity. The sum of the capacities of the new dams is known to be equal to the capacity.

Therefore, we consider the cost of developing the new area. We assume that development costs accounted for $20 \%$ of construction costs. The obvious cost of new dam system is .The potential cost is .The total cost is 30.81 billion dollars. There are 15 new dams in the new dam system. We assume that the 35 percent of the water controlling dam and the water storage irrigation dam's capacity is used to generate electricity. The yield per cubic meter of water used for agricultural irrigation is about 1.3 times that of electricity generation, and $85 \%$ of the proceeds of electricity generation are used to regulate water resources. The new dam system's profit is 1550.80 billion dollars.

\section{Reference}

[1]. Ming Zhang. Exploration on Geological Prospecting of Dam Location in Water Conservancy Project[J]. Jiangxi building materials. Vol. 9 (2016) No.9, p. 107-107.

[2]. Information on: http://www.mofcom.gov.cn/article/i/jyjl/k/201501/20150100864271.shtml

[3]. Shoukui Si, Xijing Sun. Mathematical Modeling Algorithms and Applications (2nd Edition)[M]. National Defense Industry Press,2011 